\title{
RESPONSABILIDAD SOCIAL EMPRESARIAL: INCLUSIÓN FINANCIERA EN EL SISTEMA BANCARIO PRIVADO ECUATORIANO
}

\section{CORPORATE SOCIAL RESPONSIBILITY: FINANCIAL INCLUSION IN THE ECUADORIAN PRIVATE BANKING SYSTEM}

\author{
Galo Ramiro Acosta Palomeque \\ Departamento de Ciencias Económicas, Administrativas y de Comercio \\ Universidad de las Fuerzas Armadas ESPE \\ Sangolquí, Pichincha, Ecuador \\ gracosta@espe.edu.ec
}

Fecha de recepción: 27/04/2018 - Fecha de aprobación: 07/08/2018

\section{RESUMEN}

Según el Banco Mundial se calcula que en el planeta más de 2.000 millones de adultos no tienen una cuenta para realizar transacciones, más de 200 millones de micro, pequeñas y medianas empresas carecen de financiamiento. Según Global Findex en Ecuador, aproximadamente, el $46,2 \%$ de la población ecuatoriana mayor a 15 años tenía una cuenta en una institución financiera formal en el año 2014. El presente estudio tiene como objetivo evaluar la inclusión financiera en el sistema bancario privado ecuatoriano a partir de las memorias de sostenibilidad del año 2016. En la investigación, para la elaboración del marco teórico se utilizó una metodología de investigación documental y descriptiva, mientras que para el estudio empírico se empleó el esquema metodológico de la fenomenología de tipo transversal y se escogieron a 4 instituciones financieras. Las instituciones financieras analizadas presentan un enfoque instrumentalista de responsabilidad social empresarial. La evidencia sugiere que a partir de la Constitución de 2008 se ha ido configurando un entorno regulatorio e institucional propicio para la inclusión financiera. Finalmente, durante el año 2016 se observa una mejora en el uso y acceso a los productos y servicios financieros.

PALABRAS CLAVE: Inclusión financiera; Memorias de sostenibilidad; Responsabilidad Social Empresarial; Sistema bancario.

\section{ABSTRACT}

According to the World Bank, it is estimated that more than 2 billion adults on the planet do not have an account to transact, more than 200 million micro, small and medium enterprises lack businesses. According to Global Findex in Ecuador, approximately, $46.2 \%$ of the Ecuadorian population over 15 years of age had an account in a formal financial institution in

\footnotetext{
"Visión de Futuro" Año 16, Volumen No 23 N¹, Enero - Junio 2019 - Pág. 115 - 137

URL de la Revista: http://revistacientifica.fce.unam.edu.ar/

URL del Documento: http://revistacientifica.fce.unam.edu.ar/index.php?option=com content\&view=article\&id=492\&ltemid=101 
2014. The objective of this study is the financial inclusion in the Ecuadorian private banking system based on the sustainability reports of the year 2016. In the research, a methodology of documentary and descriptive research was used for the elaboration of the theoretical framework, while for the empirical study the methodological scheme of the transversal-type phenomenology was used and 4 financial institutions. The analyzed financial institutions present an instrumentalist approach to corporate social responsibility. The evidence suggests that, starting with the 2008 Constitution, a regulatory and institutional environment for financial inclusion has been formed. Finally, during 2016 there was an improvement in the use and access to financial products and services.

KEY WORDS: Financial inclusion; Sustainability reports; Corporate social responsibility; Bank System.

\section{INTRODUCCIÓN}

En los últimos años la inclusión financiera (IF) se ha convertido en un tema importante de investigación. La OECD (2013) define a la IF como el acceso oportuno y adecuado a una gama de productos y servicios regulados y al aumento de su uso por parte de todos los segmentos de la sociedad. En el contexto mundial la IF es tan relevante que consta como una meta de los Objetivos de Desarrollo Sostenible (ODS) de la Agenda 2030 aprobada por la Organización de las Naciones Unidas (ONU). El Banco Mundial promociona el acceso universal a productos y servicios financieros para el 2020 (UFA 2020).

Según el Banco Mundial (2016) se calcula que en el planeta más de 2.000 millones de adultos no disponen de una cuenta básica para realizar sus transacciones, más de 200 millones de MIPYMES carecen del financiamiento adecuado para crecer y prosperar. En Ecuador la utilización de servicios financieros en los últimos años ha avanzado de forma moderada. Según los últimos datos de Global Índex del Banco Mundial muestran que en el 2014 aproximadamente el 46,2\% de la población ecuatoriana mayor a 15 años tenía una cuenta en una institución financiera formal, mientras el promedio en América Latina y el Caribe era $51,1 \%$, y $70,4 \%$ en países con ingresos medios altos.

Así, los objetivos del presente trabajo consistieron en realizar un análisis de revisión documental de las variables responsabilidad social empresarial e inclusión financiera, como también evaluar la inclusión financiera en 4 bancos grandes ecuatorianos a partir de las memorias de sostenibilidad del año 2016.

El resto del documento está organizado de la siguiente manera: la sección 1 describe la metodología empleada para realizar los estudios documental y empírico. En la sección 2 se

\footnotetext{
"Visión de Futuro" Año 16, Volumen No 23 N¹, Enero - Junio 2019 - Pág. 115 - 137

URL de la Revista: http://revistacientifica.fce.unam.edu.ar/

URL del Documento: http://revistacientifica.fce.unam.edu.ar/index.php?option=com content\&view=article\&id=492\&ltemid=101 
revisa el marco teórico relacionado con la responsabilidad social y la inclusión financiera. La sección 3 recoge los resultados empíricos y finalmente se presentan las principales conclusiones.

\section{DESARROLLO}

\section{Metodología}

1.1 Estudio documental:

En el marco teórico se utilizó una metodología de investigación documental y descriptiva, dado que el procedimiento implica la búsqueda, organización, sistematización y análisis de documentación sobre la responsabilidad social empresarial (RSE), la inclusión financiera, guías e indicadores de responsabilidad social a nivel general y del sector financiero, y entorno regulatorio de la inclusión financiera en el Ecuador.

Las unidades de análisis fueron todos los documentos sobre el tema encontrados en las bases de datos de organismos oficiales, Instituciones Financieras y en Google Académico. Como criterios de búsqueda, se incluyeron los siguientes descriptores: responsabilidad social empresarial, inclusión financiera, pacto global, objetivos de desarrollo sostenible, global reporting initiave, memorias de sostenibilidad, entre otros. Estos descriptores fueron combinados de diferentes formas para ampliar los criterios de exploración. Al realizar la búsqueda de información se escogieron 49 fuentes como libros físicos y digitales; artículos de bases de datos indexadas; leyes, resoluciones, regulaciones y se revisaron sistemáticamente estos documentos.

Para la organización de los documentos se creó una base de datos con los siguientes campos: título de la publicación, autor, año, editor, objetivos, tipo de investigación, método, resultados y núcleo temático. Una vez organizada la información, se agruparon los documentos por núcleos temáticos. Posteriormente, se realizó el análisis de cada uno de los núcleos temáticos. Finalmente, se efectuó un análisis global mediante el cual se identificaron los puntos fuertes y débiles de la inclusión financiera en Ecuador y se formularon ciertas conclusiones.

\subsection{Estudio empírico}

El estudio se realizó bajo el esquema metodológico de la fenomenología, es de tipo transversal y la muestra es de naturaleza no probabilística. En primer lugar, se clasificó a las 23 instituciones bancarias ecuatorianas por su tamaño según el ranking financiero desarrollado por Ekos. En este sentido, Ekos utilizó la metodología CAMEL y los estados financieros correspondientes al año 2016. El número de bancos segmentados por su tamaño se presenta en la tabla $\mathrm{N}^{\circ} 1$.

\footnotetext{
"Visión de Futuro" Año 16, Volumen No 23 Nº1, Enero - Junio 2019 - Pág. 115 - 137

URL de la Revista: http://revistacientifica.fce.unam.edu.ar/

URL del Documento: http://revistacientifica.fce.unam.edu.ar/index.php?option=com content\&view=article\&id=492\&ltemid=101 
Tabla N`1. Segmentación de las entidades bancarias por su tamaño

\begin{tabular}{llc}
\hline \multicolumn{1}{c}{ Tipo de Banco } & \multicolumn{1}{c}{ Monto de Activos } & $\begin{array}{c}\text { Cantidad de } \\
\text { Bancos }\end{array}$ \\
\hline Bancos grandes & ( >1.000 millones de USD) & 7 \\
Bancos medianos & (entre 200 y 1.000 millones de USD) & 6 \\
Bancos pequeños & $(<200$ millones de USD) & 10 \\
\hline
\end{tabular}

Fuente: Elaboración Propia en base a Ekos (2017)

En segundo lugar, se revisó en los sitios web, de las instituciones bancarias grandes que publicaron las memorias de sostenibilidad en los últimos 3 años, obteniéndose los resultados que se muestran en la Tabla $N^{\circ} 2$.

Tabla $N^{\circ}$ 2. Bancos grandes que publican memorias de sostenibilidad

\begin{tabular}{clccc}
\hline No. & Institución Financiera & $\mathbf{2 0 1 4}$ & $\mathbf{2 0 1 5}$ & $\mathbf{2 0 1 6}$ \\
\hline 1 & Internacional & & & \\
2 & Bolivariano & $\mathrm{X}$ & $\mathrm{X}$ & $\mathrm{X}$ \\
3 & Produbanco & $\mathrm{X}$ & $\mathrm{X}$ & $\mathrm{X}$ \\
4 & Pacífico & $\mathrm{X}$ & $\mathrm{X}$ & $\mathrm{X}$ \\
5 & Guayaquil & $\mathrm{X}$ & $\mathrm{X}$ & $\mathrm{X}$ \\
6 & Pichincha & & & \\
7 & Austro & & \\
\hline
\end{tabular}

Fuente: Elaboración Propia

En este estudio se analizó la responsabilidad social empresarial, puntualmente, el tema de la inclusión financiera. Se escogieron a las instituciones financieras Produbanco, Pacífico, Guayaquil y Pichincha, que publicaron la memoria de sostenibilidad en el año 2016. De acuerdo a Ekos (2017) los bancos privados representan el 80\% del total del sistema financiero, mientras que los siete bancos grandes el $88 \%$ del total del sistema bancario y el $70 \%$ del sistema financiero privado.

\section{Revisión de la Literatura}

La revisión de literatura se realizó sobre dos variables principales que abordan la investigación: responsabilidad social empresarial (RSE) e inclusión financiera (IF); a continuación se definen cada una de ellas.

\subsection{La responsabilidad social empresarial (RSE)}

La Responsabilidad Social Empresarial (RSE) entendida como una forma ética de gestión de las organizaciones, en particular de las instituciones financieras, orienta sus actividades tomando en cuenta las expectativas de los diferentes grupos de interés afectados por sus acciones (accionistas/inversionistas, clientes, colaboradores y sus familias, comunidad, medio ambiente y gobierno); contribuye al desarrollo sostenible.

\footnotetext{
"Visión de Futuro" Año 16, Volumen No 23 N¹, Enero - Junio 2019 - Pág. 115 - 137

URL de la Revista: http://revistacientifica.fce.unam.edu.ar/

URL del Documento: http://revistacientifica.fce.unam.edu.ar/index.php?option=com content\&view=article\&id=492\&/temid=101 
La definición más consensuada a nivel global es la generada por la International Organization for Standardization ISO (2010), se refiere a la responsabilidad social como un comportamiento ético y transparente en la toma de decisiones y en las actividades empresariales que tiene impacto en la sociedad y el medio ambiente, que contribuye al desarrollo sostenible y al bienestar de la comunidad, que toma en cuenta las expectativas de las partes interesadas, que cumple la legislación vigente y es coherente con la normativa internacional de comportamiento organizacional socialmente responsable. La importancia de la transparencia en los negocios en la actualidad que, junto con la ética, exigen un accionar empresarial acorde con las necesidades del entorno (Marulanda , 2014).

El triple resultado (triple bottom line) acuñado por Elkington (1994) es un término relacionado con los negocios sostenibles, que hace referencia al desempeño de una empresa expresado en las dimensiones social, ambiental y económica, que permite una visualización interna y externa de una organización.

El triple bottom line (TBL) fue más allá de las tradicionales medidas de los beneficios, rentabilidad de la inversión y valor para el accionista al incluir las dimensiones social y ambiental. EI TBL se calcula mayoritariamente en términos de un índice, teniendo la ventaja de que permite realizar comparaciones entre empresas, ciudades, proyectos de desarrollo, entre otros (Slaper \& Hall, 2011). Las principales características que presentan estas tres dimensiones se muestran en la Tabla $\mathrm{N}^{\circ} 3$.

Tabla $N^{\circ}$ 3. Dimensiones de la RSE

\begin{tabular}{|c|c|c|}
\hline Dimensión & Interna & Externa \\
\hline \multirow[t]{6}{*}{ Económica } & -Enfoque en la generación de & - Producción y distribución de \\
\hline & $\begin{array}{l}\text { valor agregado para sus } \\
\text { accionistas y colaboradores, }\end{array}$ & $\begin{array}{l}\text { bienes y servicios rentables } \\
\text { para la sociedad. }\end{array}$ \\
\hline & $\begin{array}{l}\text { tomando en cuenta las } \\
\text { condiciones de mercado, con }\end{array}$ & $\begin{array}{l}\text { - Aporte a la sociedad vía } \\
\text { impositiva. }\end{array}$ \\
\hline & equidad y justicia. & - A las empresas les \\
\hline & -Se espera que la empresa & corresponde participar en los \\
\hline & $\begin{array}{l}\text { genere utilidades y que se } \\
\text { mantenga viva. }\end{array}$ & $\begin{array}{l}\text { planes económicos de sus } \\
\text { regiones y países. }\end{array}$ \\
\hline \multirow[t]{3}{*}{ Social } & - Involucra la responsabilidad & - Ejecución de \\
\hline & compartida de sus & propias y gremiales que \\
\hline & $\begin{array}{l}\text { integrantes para el fomento } \\
\text { de la calidad de vida en el } \\
\text { trabajo y el desarrollo integral } \\
\text { de todos. }\end{array}$ & $\begin{array}{l}\text { contribuyan con tiempo y } \\
\text { recursos que favorezcan el } \\
\text { desarrollo } \\
\text { comunidades. }\end{array}$ \\
\hline Ambiental & $\begin{array}{l}\text { - Responsabilidad total sobre } \\
\text { los efectos ambientales de } \\
\text { sus procesos, productos y } \\
\text { subproductos. }\end{array}$ & $\begin{array}{l}\text { - Ejecución de acciones } \\
\text { específicas que contribuyan a } \\
\text { la preservación y mejora de la } \\
\text { herencia ecológica común. }\end{array}$ \\
\hline
\end{tabular}

Para Noé, Buraschi y Peretti (2015) la RSE se basa en dar respuesta, principalmente, a las demandas originadas en las dimensiones social y ambiental, pretendiendo integrarlas con el objetivo económico primario de rentabilidad. Si las empresas contemplaran a la RSE de "Visión de Futuro" Año 16, Volumen N²3 N¹, Enero - Junio 2019 - Pág. 115 - 137 URL de la Revista: http://revistacientifica.fce.unam.edu.ar/

URL del Documento: http://revistacientifica.fce.unam.edu.ar/index.php?option=com content\&view=article\&id=492\&/temid=101 ISSN 1668 - 8708 - Versión en Línea

E-mail: revistacientifica@fce.unam.edu.ar 
manera estratégica, sería una fuente de oportunidades que generaría una ventaja competitiva y beneficios en términos de ciudadanía corporativa, trabajando de manera cooperativa con sus proveedores, clientes, competencia y otras partes interesadas (Elkington, 1994).

Rivera y Malaver (2011) agrupan a la responsabilidad social en los siguientes cuatro enfoques: a) teoría instrumental, b) teoría política, c) teoría integradora y d) teoría ética. El enfoque instrumental considera a la RSE como una herramienta estratégica para la creación de valor y a las actividades sociales como un medio para alcanzar resultados económicos. Se divide en tres subcategorías: a) Maximización del valor para los accionistas; b) Estrategias para lograr ventajas competitivas y c) Marketing relacionado con alguna causa (Rubio \& Fierro, 2016). Las empresas asumen un comportamiento ético y responsable en la medida que obtengan ventajas competitivas.

\subsection{La inclusión financiera}

El Banco Mundial (2016) se refiere a la inclusión financiera como la accesibilidad que tienen las empresas y las personas a una gama de productos y servicios financieros que satisfagan sus necesidades y que son proporcionados de modo sostenible y responsable. Esta perspectiva tiene muchas dimensiones según la cantidad de servicios que se incorporen y está dirigida de manera diferente a los individuos y a las empresas. El acceso a servicios financieros como la apertura de una cuenta de ahorros, facilita la utilización de medios de pago electrónicos, la realización de transferencias, la generación de ahorro, y al crearse un colateral la posibilidad de acceder a créditos, seguros y productos financieros más elaborados (Cueva, 2012).

La inclusión financiera se relaciona con la teoría de la base de la pirámide propuesta por Prahalad (2005) que consiste en que las empresas deben tomar en cuenta a la población de bajos ingresos como potenciales consumidores, proveedores, distribuidores, socios o empleados, ya que representan una oportunidad para erradicar la pobreza a la vez que generan rentabilidad. En este sentido, los negocios inclusivos (NI) son iniciativas empresariales sostenibles con el potencial de mejorar significativamente las condiciones de vida de la población de la base de la pirámide (Bpd), al mismo tiempo que son económicamente rentables y ambientalmente viables (Pineda, 2014).

Para Prahalad (2005) el mercado de pobres permitiría explotar las llamadas economías de escala en la telefonía celular, servicios de salud y en los créditos masivos. En Ecuador a marzo del 2016, la población pobre representó el 25,35\% del total. Un ejemplo de inclusión de la población de la base de la pirámide en Ecuador tiene que ver con la expansión del mercado de la telefonía celular, a diciembre de 2017 existían 14.651 .404 líneas activas a nivel nacional de servicio de telefonía móvil, representando una tasa de penetración del $89 \%$. El

\footnotetext{
"Visión de Futuro" Año 16, Volumen N²3 N¹, Enero - Junio 2019 - Pág. 115 - 137

URL de la Revista: http://revistacientifica.fce.unam.edu.ar/

URL del Documento: http://revistacientifica.fce.unam.edu.ar/index.php?option=com content\&view=article\&id=492\&/temid=101

ISSN 1668 - 8708 - Versión en Línea

E-mail: revistacientifica@fce.unam.edu.ar
} 
mayor acceso a las telecomunicaciones ha permitido que los trabajadores independientes porten su oficina, ganen mercados y eficiencia.

Según Levine, Loaiza y Beck (2000) la importancia del impacto de la inclusión financiera en el desarrollo de un país, se evidencia por una correlación positiva alta entre acceso a servicios financieros y el crecimiento económico de los países. De acuerdo a Sahay, Cihák, N’Diaye y Barajas (2015) en la década del 2000 los estudios empíricos sobre este constructo evolucionaron con la aplicación de la técnica estadística de datos panel con valores rezagados en las variables financieras y controlándose el efecto de otros determinantes del crecimiento. Aizenman, Jijarak, y Park (2015) analizan los datos a nivel sectorial de 41 economías, determinan que la profundización financiera aumenta el crecimiento económico pero solo hasta cierto punto, además, de tener efectos heterogéneos entre los diferentes sectores. El mayor crecimiento económico se produce, gracias al aumento de la capacidad de consumo y por la expansión de la inversión por parte de la población excluida.

La inclusión financiera es un concepto que contempla varios elementos complementarios que se observan en la figura $\mathrm{N}^{\circ} 1$ : a) un entorno regulatorio adecuado, b) una oferta de productos propicios (medios de pago, ahorros, créditos y seguros), c) una cobertura del sector financiero, con acceso a todos los canales transaccionales para recibir servicios de calidad a precios justos, d) fomento y difusión de la educación financiera y e) adecuada protección al consumidor de servicios financieros y transparencia en la información.

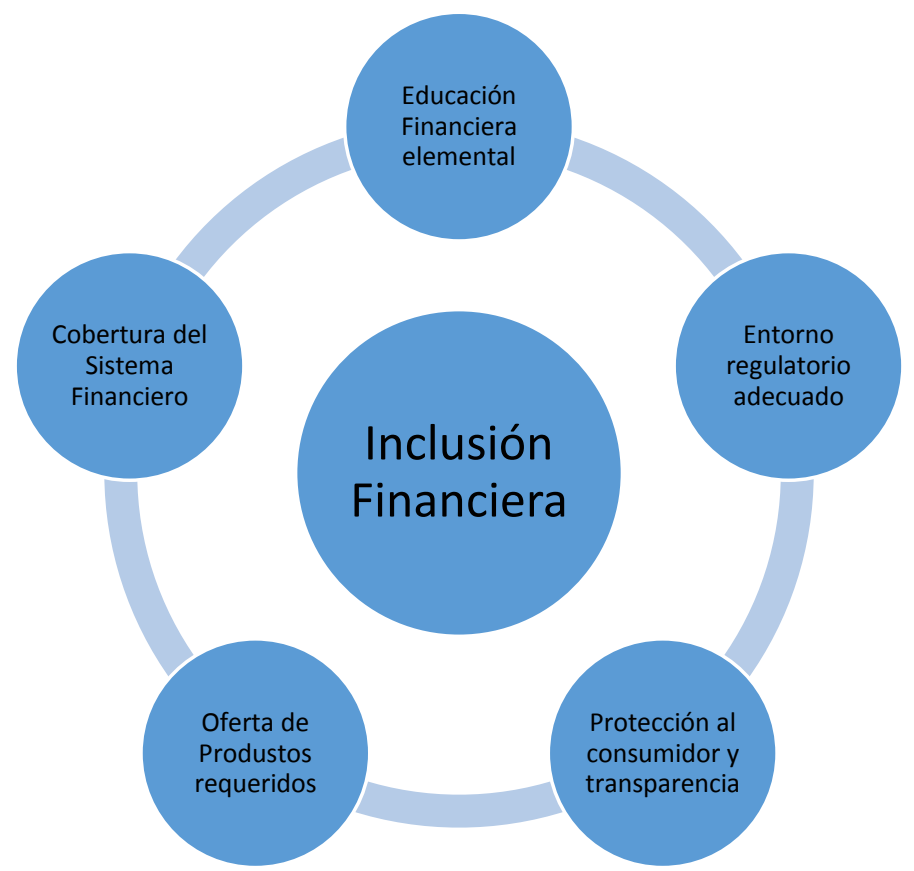

Figura $\mathrm{N}^{\circ}$ 1. Elementos de la Inclusión Financiera (IF)

Fuente: Elaboración a partir de Moya (2011)

\footnotetext{
"Visión de Futuro" Año 16, Volumen No 23 Nº 1, Enero - Junio 2019 - Pág. 115 - 137

URL de la Revista: http://revistacientifica.fce.unam.edu.ar/

URL del Documento: http://revistacientifica.fce.unam.edu.ar/index.php?option=com content\&view=article\&id=492\&ltemid=101 
Las micro, pequeñas, y medianas empresas (MIPYMES), en general, enfrentan diversas barreras de acceso al sistema financiero, al igual que la población de menores ingresos. Las barreras a la inclusión financiera se clasifican desde la oferta y la demanda como se observa en la Tabla $\mathrm{N}^{\circ} 4$.

Tabla $\mathrm{N}^{\circ}$ 4. Barreras de acceso al sistema financiero

\begin{tabular}{ll}
\hline Dimensión & \multicolumn{1}{c}{ Barrera de acceso } \\
\hline Oferta & $\begin{array}{l}\text { Costos de acercar la prestación de servicios financieros a los usuarios } \\
\text { Oificultades para asumir el riesgo en cierto tipo de operaciones por } \\
\text { asimetrías de información, falta de normatividad, controles de tasas de } \\
\text { interés y préstamos dirigidos }\end{array}$ \\
Oferta & $\begin{array}{l}\text { Una mayor carga regulatoria } \\
\text { La adopción de estándares de regulación prudencial como los lineamientos } \\
\text { de Basilea II y III }\end{array}$ \\
Oferta & $\begin{array}{l}\text { Los lineamientos del GAFI con respecto al lavado de dinero y financiamiento } \\
\text { del terrorismo }\end{array}$ \\
Oferta & Bajos ingresos \\
Demanda & Precios altos de los servicios \\
Demanda & Escasa educación financiera \\
Demanda & Factores culturales \\
\hline
\end{tabular}

Fuente: Elaborado en base a Guerrero, Espinosa y Focke (2012)

La oferta y demanda combinada, determinan el segmento de la población bancarizable. En este sentido, para Guerrero, Espinosa y Focke (2012) un sistema financiero inclusivo significa poner al alcance de las empresas y personas de menores ingresos todo tipo de servicios financieros como, por ejemplo, apertura de cuentas, envío de remesas, ahorros, microcréditos, tarjetas de crédito, créditos para vivienda hasta seguros.

Índice multidimensional de inclusión financiera (MIFI): EI MIFI es utilizado para comparar los niveles de inclusión financiera entre las economías de los países en el tiempo. Un sistema financiero inclusivo maximiza el acceso y uso, mientras minimiza las barreras que limitan la inclusión financiera (Cámara \& Tuesta, 2014). En este sentido, el MIFI evalúa tres dimensiones: el uso, acceso y barreras mediante indicadores que se muestran en la Tabla $N^{\circ} 5$. Los pesos asignados a las dimensiones están determinados por la técnica estadística del Análisis de Componentes Principales en dos etapas.

Tabla $\mathrm{N}^{\circ}$ 5. Índice multidimensional de la inclusión financiera (MIFI)

\begin{tabular}{ll}
\hline \multicolumn{1}{c}{ Dimensión } & \multicolumn{1}{c}{ Indicadores } \\
\hline Uso & Existencia de productos y servicios financieros formales, \\
& usuarios que posean al menos una cuenta o tarjeta, \\
& tenencia de ahorros, préstamos \\
Acceso & Número de puntos de atención personal como oficinas \\
& bancarias y corresponsales; y acceso a través de cajeros \\
& automáticos
\end{tabular}

\footnotetext{
"Visión de Futuro" Año 16, Volumen No 23 N¹, Enero - Junio 2019 - Pág. 115 - 137

URL de la Revista: http://revistacientifica.fce.unam.edu.ar/

URL del Documento: http://revistacientifica.fce.unam.edu.ar/index.php?option=com content\&view=article\&id=492\&ltemid=101 
Barreras

Confianza en el sistema financiero formal, costo de los servicios financieros, distancia a los puntos de acceso y documentación requerida

\section{Fuente: Elaborado en base a Cámara y Tuesta (2014)}

El índice Multidimensional de Inclusión Financiera en el 2014 se calculó para 137 países, basado tanto en información del lado de la demanda usando los datos del Global Findex, como de la oferta a partir de la encuesta de acceso financiero del Fondo Monetario Internacional. En Latinoamérica los 10 primeros países en inclusión financiera de acuerdo al MIFI 2014 se presentan en la Tabla $N^{\circ}$ 6; como se puede observar la mayoría presenta un nivel medio de inclusión financiera.

Tabla $N^{\circ}$ 6. Ranking de Inclusión Financiera MIFI 2014 en Latinoamérica

\begin{tabular}{cllc}
\hline $\begin{array}{c}\text { Ranking } \\
\text { Latinoamérica }\end{array}$ & \multicolumn{1}{c}{ País } & Categoría MIFI & Ranking global \\
\hline 1 & Brasil & Elevado & 4 \\
2 & Chile & Alto & 31 \\
3 & Colombia & Alto & 36 \\
4 & Costa Rica & Medio & 43 \\
5 & Uruguay & Medio & 56 \\
6 & Ecuador & Medio & 57 \\
7 & Venezuela & Medio & 62 \\
8 & Perú & Medio & 68 \\
9 & Argentina & Medio & 70 \\
10 & República Dominicana $\quad$ Medio & 71 \\
\hline
\end{tabular}

Para Cámara y Tuesta (2014) el grado de inclusión financiera de los países está altamente correlacionado con las siguientes variables: PIB per cápita, educación financiera, eficiencia del sistema financiero y con la estabilidad financiera.

\subsection{Guías e indicadores de Responsabilidad social a nivel general}

Las guías de responsabilidad social orientan los esfuerzos de todos los actores para avanzar hacia un desarrollo sostenible centrado en la igualdad. Las principales iniciativas a las que se encuentran adheridas las organizaciones son el Pacto Global y los Objetivos de Desarrollo Sostenible (ODS), entre otras.

EI Pacto Mundial: El Pacto global es una iniciativa voluntaria, en que las empresas hacen el compromiso de alinear sus operaciones y estrategias con los diez principios en las áreas de medio ambiente, derechos humanos, estándares laborales y anticorrupción, como también contribuir con los Objetivos de Desarrollo Sostenible (ODS). Según United Nations Global Compact (2018) por su número de participantes, 9704 empresas en más de 161 países, el Pacto Global es la iniciativa más grande a nivel mundial. Las organizaciones adheridas tienen la seguridad de que las prácticas basadas en principios universales coadyuvan a un mercado mundial más inclusivo, estable y equitativo (Pacto Global Red Colombia, 2018).

\footnotetext{
"Visión de Futuro" Año 16, Volumen No 23 Nº1, Enero - Junio 2019 - Pág. 115 - 137

URL de la Revista: http://revistacientifica.fce.unam.edu.ar/

URL del Documento: http://revistacientifica.fce.unam.edu.ar/index.php?option=com content\&view=article\&id=492\&ltemid=101 
Objetivos de Desarrollo Sostenible (ODS): En septiembre de 2015, la Asamblea General de las Naciones Unidas aprobó la Agenda 2030 para el Desarrollo Sostenible, integra 17 objetivos y 169 metas. Según Naciones Unidas (2016) esta agenda procura una trasformación hacia la sostenibilidad social, económica y ambiental de los 193 estados adheridos. Es una guía para el trabajo de las organizaciones, constituye una oportunidad para Latinoamérica y el Caribe, debido a que se incluyen temas prioritarios como la reducción de las desigualdades, impulsa el crecimiento económico inclusivo con trabajo decente, entre otros. En el caso de América Latina y el Caribe en donde la mayoría de los países son considerados de renta media, el financiamiento para la Agenda 2030 tendrá que ser cubierto con recursos privados y públicos y por fuentes innovadoras.

Los objetivos de desarrollo sostenible, en adelante ODS, ponen especial énfasis en frenar el aumento de la desigualdad, especialmente, en el ámbito económico. En este sentido, se promueve la inclusión financiera como una de las principales prioridades hasta el 2030 . El ODS 8, promover el crecimiento económico sostenido, inclusivo y sostenible, se relaciona con la inclusión financiera, específicamente, con la meta 10, que consiste en fortalecer la capacidad de las entidades financieras de los países para incrementar la accesibilidad a los servicios financieros formales y de seguros hasta el 2030. (Naciones Unidas, 2018)

Para Rodriguez y Segura (2013) los indicadores de gestión responsable se han generado para que las empresas sean reconocidas como socialmente responsables y su propósito es medir el cumplimiento de sus objetivos en cada una de las dimensiones de la RSE. En Ecuador, las empresas utilizan la Global Reporting Initiative (GRI), la ISO 26000 y el índice de sostenibilidad Dow Jones (DJSI), entre otros.

Global Reporting Initiative (GRI): Global Sustainability Standards Board (2016) menciona que los estándares GRI para la elaboración de informes de sostenibilidad se han diseñado para que las organizaciones presenten la información sobre sus impactos en la sociedad, economía y medio ambiente. Los estándares GRI se han desarrollado, principalmente, para utilizarse como un conjunto interrelacionado que ayude en la preparación de informes de sostenibilidad a las organizaciones del cualquier tipo, sector, tamaño o ubicación geográfica.

ISO 26000: La ISO 26000 es una Norma Internacional que brinda una guía en responsabilidad social. Está elaborada para todo tipo de organización, tanto pública como privada en todos los países. La norma ayuda a las organizaciones a funcionar de manera socialmente responsable en una sociedad cada vez más exigente. La ISO 26000 se compone de guías voluntarias, más no requisitos, por lo que no se debe utilizar como una norma de certificación (ISO, 2010). Según Global Reporting Initiative (2011) existe una relación entre

"Visión de Futuro" Año 16, Volumen No 23 N¹, Enero - Junio 2019 - Pág. 115 - 137

URL de la Revista: http://revistacientifica.fce.unam.edu.ar/

URL del Documento: http://revistacientifica.fce.unam.edu.ar/index.php?option=com content\&view=article\&id=492\&/temid=101 
las orientaciones del GRI para elaborar los reportes de sostenibilidad y las orientaciones de Responsabilidad Social (RS) de la norma ISO 26000.

Índice de Sostenibilidad Dow Jones (DJSI): Es un índice mundial que valora las buenas prácticas de sostenibilidad de las empresas bajo criterios sociales, ambientales y económicos. Este índice se ha convertido en un punto de referencia para aquellos inversores que toman en cuenta los criterios de sostenibilidad en el momento de invertir en el mercado de valores (RobecoSam, 2018).

La banca ecuatoriana ha venido adoptando estas guías e indicadores de gestión dentro de sus actividades, por ejemplo, Banco Pichincha se encuentra adherido a la iniciativa del Pacto Mundial desde el año 2011, comprometiéndose desde entonces, a alinear su modelo de gestión sostenible con los 10 principios universalmente aceptados. Asimismo, para la elaboración de las memorias de sostenibilidad los bancos ecuatorianos se acogen a los lineamientos de la Global Reporting Iniative (GRI).

\subsection{Guías e indicadores de Responsabilidad social en el sector financiero}

En lo relacionado a la gestión responsable del sistema financiero, a nivel mundial se han elaborado guías e indicadores que propenden al desarrollo sostenible en temas como los que se indican en la Tabla $N^{\circ} 7$.

Tabla $\mathbf{N}^{\circ}$ 7. Guías e indicadores en el sector financiero

\begin{tabular}{|c|c|}
\hline Autor & Guía o Indicador \\
\hline International Finance & Los principios de Ecuador: Un punto de referencia de la industria \\
\hline Corporation (2013) & $\begin{array}{l}\text { financiera para determinar, evaluar y gestionar los riesgos sociales } \\
\text { y ambientales en proyectos. }\end{array}$ \\
\hline $\begin{array}{l}\text { Corporación Financiera } \\
\text { Internacional ( 2012) }\end{array}$ & Gestión del riesgo ambiental y social para instituciones financieras. \\
\hline $\begin{array}{l}\text { The Smart Campaign } \\
\text { (2011), OECD (2011), } \\
\text { Mazer, Rafe y Mckee, } \\
\text { (2017) }\end{array}$ & $\begin{array}{l}\text { Los principios de protección al cliente: promueven la inclusión y } \\
\text { educación financiera. }\end{array}$ \\
\hline $\begin{array}{l}\text { Global Banking Aliance } \\
\text { for Women (2018) }\end{array}$ & $\begin{array}{l}\text { Alianza global de bancos para la mujer: Sus miembros trabajan en } \\
\text { todo el mundo, ayudándose unos a otros a crear programas } \\
\text { rentables y sostenibles para el mercado de mujeres. }\end{array}$ \\
\hline
\end{tabular}

Fuente: Elaboración Propia

\section{Resultados}

\subsection{Entorno regulatorio de la inclusión financiera en Ecuador}

Ecuador tiene una larga trayectoria en instituciones dedicadas a las microfinanzas, vinculadas, principalmente, al cooperativismo. Las asociaciones gremiales y cooperativas datan desde 1879 al conformarse en la ciudad de Guayaquil, la Sociedad de Artesanos Amantes del Progreso. En el año 2002, según la Red Financiera Rural (RFR) 15 organizaciones no gubernamentales y 2 instituciones bancarias se dedicaban al segmento de

\footnotetext{
"Visión de Futuro" Año 16, Volumen N²3 N¹, Enero - Junio 2019 - Pág. 115 - 137

URL de la Revista: http://revistacientifica.fce.unam.edu.ar/

URL del Documento: http://revistacientifica.fce.unam.edu.ar/index.php?option=com content\&view=article\&id=492\&/temid=101 
microcréditos, otorgando 95.124.993 dólares para atender alrededor de 192.849 clientes. Sin embargo, la inclusión financiera en el Ecuador inicia, formalmente, con la Constitución vigente desde el año 2008, de ahí en adelante se ha ido configurando el actual marco legal que se presenta en la Tabla $N^{\circ} 8$.

Tabla $N^{\circ}$ 8. Marco regulatorio de la inclusión financiera en Ecuador

\begin{tabular}{ll}
\hline \multicolumn{1}{c}{ Marco Legal } & \multicolumn{1}{c}{ Contenido } \\
\hline Constitución de la República del Ecuador & Art. 283 estipula que el sistema económico es social \\
Asamblea Constituyente (2008). & $\begin{array}{l}\text { y solidario, estará integrado por las formas de } \\
\text { organización pública, privada, mixta, popular y } \\
\text { solidaria. }\end{array}$
\end{tabular}

Art. 309 dispone que el sistema financiero ecuatoriano estará conformado por los sectores público, privado, popular y solidario.

Art. 311 estipula que el sector financiero popular y solidario se compondrá de cooperativas de ahorro y crédito, entidades asociativas o solidarias, cajas y bancos comunales y cajas de ahorro.

Ley de Economía Popular y Solidaria y del Sector Financiero Popular y Solidario Presidencia de la República (2011).

Resolución No JB-2008-1150 de la Junta Bancaria del Ecuador (2008).

Regulación No. 024-2012 del Banco Central del Ecuador (2012)

Código Orgánico Monetario y Financiero Asamblea Nacional (2014)

Tiene como objetivo establecer un marco jurídico para las personas naturales o jurídicas que integran la Economía Popular y Solidaria y el sector financiero popular y solidario.

Se autoriza a las instituciones financieras a tener corresponsales no bancarios, para que presten sus servicios financieros correspondientes al pago de servicios básicos, recepción de depósitos, retiros de efectivo con tarjeta de débito, pago del bono de desarrollo humano, entre otros.

El Banco Central del Ecuador norma la operación de los Sistemas Red de Redes y el Sistema de Pago móvil como un mecanismo para ampliar el acceso y la utilización de los servicios financieros formales a la población excluida o limitada. Siendo estos sistemas administrados por el Banco Central del Ecuador.

El Banco Central del Ecuador tendrá la función de incentivar la inclusión financiera, aumentando la accesibilidad a servicios financieros de calidad.

Resolución No. 005-2014-M de la Junta de Política y Regulación Monetaria y Financiera (2014)

Permite la implementación del dinero electrónico gestionado privativamente por el Banco Central del Ecuador, se intercambia a través de dispositivos electrónicos, móviles, electromecánicos, fijos, tarjetas inteligentes, computadoras y otros.

Ley Orgánica para la Reactivación de la Economía, fortalecimiento de la dolarización y modernización de la gestión financiera Presidencia de la República del Ecuador (2017).

Resolución No. 437-2018-F de la Junta de Política y Regulación Monetaria y Financiera (2018).

Se asigna al Banco Central del Ecuador la función de regular, controlar, monitorear y evaluar la gestión de los medios de pagos electrónicos operados por el sistema financiero nacional.

Con esta resolución se reduce en $2 \%$ la tasa de interés efectiva anual máxima para el segmento de microcrédito.

Fuente: Elaboración propia, en base a las memorias de sustentabilidad

En Ecuador durante el período 2008-2018, a través del nuevo marco legal se asientan

las bases para el desarrollo de la inclusión financiera, se autoriza a las instituciones financieras

\footnotetext{
"Visión de Futuro" Año 16, Volumen No 23 N¹, Enero - Junio 2019 - Pág. 115 - 137

URL de la Revista: http://revistacientifica.fce.unam.edu.ar/

URL del Documento: http://revistacientifica.fce.unam.edu.ar/index.php?option=com_content\&view=article\&id=492\&/temid=101

ISSN 1668 - 8708 - Versión en Línea

E-mail: revistacientifica@fce.unam.edu.ar
} 
a tener corresponsales no bancarios. Por medio de resoluciones de las autoridades competentes se reducen las tasas de interés como los costos de los servicios financieros. Se implementa el dinero electrónico gestionado en primera instancia por el Banco Central del Ecuador, posteriormente, debido al poco atractivo de este medio de pago se transfiere su gestión a las entidades financieras. Finalmente, Ecuador ocupó el puesto 25 en el ranking del Microscopio Global 2016 elaborado por (EIU (Economist Intelligencex Unit), 2016) de los mejores entornos regulatorios e institucionales para la inclusión financiera a nivel mundial.

\subsection{Grupos de interés en el sector bancario ecuatoriano}

En las instituciones financieras, los grupos de interés son el eje central de la responsabilidad social empresarial. Las partes interesadas, son aquellos individuos o conjunto de individuos que tienen algún interés en la organización, que pueden necesitar algo de ella o pueden afectar o ser afectados por las actividades que realiza. De acuerdo a las memorias de sostenibilidad de las 4 instituciones financieras analizadas, los grupos de interés identificados se muestran en la Tabla $N^{\circ} 9$.

Tabla $N^{\circ}$ 9. Grupos de interés en el sector bancario ecuatoriano

\begin{tabular}{lcccc}
\hline \multicolumn{1}{c}{ Grupo de Interés } & Produbanco & Pacífico & Guayaquil & Pichincha \\
\hline Gobierno Corporativo (Junta & & & & $\mathrm{X}$ \\
de Accionistas, Directorio & & & & \\
Alta Gerencia) & $\mathrm{X}$ & $\mathrm{X}$ & $\mathrm{X}$ & $\mathrm{X}$ \\
Colaboradores & $\mathrm{X}$ & $\mathrm{X}$ & $\mathrm{X}$ & $\mathrm{X}$ \\
Accionistas & $\mathrm{X}$ & $\mathrm{X}$ & $\mathrm{X}$ & $\mathrm{X}$ \\
Proveedores & $\mathrm{X}$ & $\mathrm{X}$ & $\mathrm{X}$ & $\mathrm{X}$ \\
Clientes & $\mathrm{X}$ & $\mathrm{X}$ & & $\mathrm{X}$ \\
Comunidad & & $\mathrm{X}$ & & \\
Autoridades Reguladoras & & & $\mathrm{X}$ & \\
Gobierno & & $\mathrm{X}$ & \\
Medios de Comunicación & & $\mathrm{X}$ & \\
ONGs. & & $\mathrm{X}$ & \\
Corresponsales no bancarios & & & $\mathrm{X}$ & \\
\hline
\end{tabular}

Fuente: Elaboración propia, basado en Produbanco (2016), Banco del Pacífico (2016),Banco Guayaq uil (2016) y Banco Pichincha (2016)

En los 4 bancos analizados, los grupos de interés comunes son los colaboradores, accionistas, proveedores y clientes. Asimismo, se observa la importancia que el Banco de Guayaquil le presta a la inclusión financiera, al identificar como grupo de interés a los corresponsales no bancarios. Finalmente, se evidencia que no existe una lista genérica de grupos de interés en las instituciones financieras estudiadas aunque correspondan a un mismo sector.

Los grupos de interés relacionadas con las instituciones financieras analizadas se dividen en internos y externos, ellos pueden, de alguna manera, influenciar o ser influenciados

\footnotetext{
“Visión de Futuro" Año 16, Volumen No 23 Nº̂, Enero - Junio 2019 - Pág. 115 - 137

URL de la Revista: http://revistacientifica.fce.unam.edu.ar/

URL del Documento: http://revistacientifica.fce.unam.edu.ar/index.php?option=com_content\&view=article\&id=492\&/temid=101

ISSN 1668 - 8708 - Versión en Línea

E-mail: revistacientifica@fce.unam.edu.ar
} 
por los objetivos de la organización en diferentes grados, en la medida en que poseen entre uno y tres atributos básicos: poder, legitimidad y urgencia. (Mitchell, Agle, \& Wood, 1997). Los grupos de interés se presentan en la Tabla $N^{\circ} 10$.

Tabla $N^{\circ} 10$. Grupos de interés internos y externos en el sector bancario ecuatoriano

\begin{tabular}{ll}
\hline \multicolumn{1}{c}{ Grupos de interés internos } & \multicolumn{1}{c}{ Grupos de interés externos } \\
\hline Gobierno corporativo & Proveedores \\
Accionistas & Clientes \\
Colaboradores & Corresponsales no bancarios \\
& Comunidad \\
& Autoridades reguladoras \\
& ONGs \\
& Gobierno \\
& Medios de comunicación \\
\hline
\end{tabular}

Fuente: Elaboración Propia, basado en Produbanco (2016), Banco del Pacífico (2016), Banco Guayaquil (2016) y Banco Pichincha (2016)

\subsection{Análisis de la inclusión financiera a partir de las memorias de sostenibilidad}

Las memorias de sostenibilidad son la manera como las organizaciones documentan, evalúan y reportan los resultados de su gestión en un periodo determinado, acerca de su desempeño económico, ambiental y social relacionado con sus grupos de interés. El sistema bancario ecuatoriano, en particular los 4 bancos analizados, presentan estas memorias basados en los lineamientos de la Global Reporting Initiative (GRI) versión 4. A continuación se detalla la labor que vienen realizando en lo que respecta a la inclusión financiera en función de los informes de sostenibilidad presentados en el año 2016.

\subsubsection{Inclusión Financiera en Produbanco}

La memoria de responsabilidad social empresarial correspondiente al año 2016 de Produbanco fue preparada bajo los estándares de la Global Reporting Initiative (GRI) versión 4. Si bien la inclusión financiera no se presenta en un apartado de la memoria, se encuentra analizada de manera transversal, y se incluye en la tabla de indicadores.

Uso (Bancarización): En el 2016, Produbanco contaba con 698.669 clientes activos. Para hacer posible el proceso de inclusión financiera en todo el territorio ecuatoriano, al 2016 se contaban con 133.889 tarjetas de crédito activas, 12.323 comercios afiliados y 396.000 tarjetas de débito activas. La facturación con tarjeta de crédito en el 2016 se incrementó en $14.02 \%$ con respecto al 2015.

En el 2016, el crédito dirigido a las microempresas representó el $0,3 \%$ del total de la cartera bruta, mientras que crédito al sector corporativo representó el 38,41\%. Entre los años 2015 y 2016, el segmento de microcrédito presentó un crecimiento del $27,08 \%$, al cierre del 2016 se logró también una reducción del índice de cartera vencida al 2,30\%. El microcrédito en el 2016 estuvo direccionado mayoritariamente a las actividades económicas relacionadas

\footnotetext{
"Visión de Futuro" Año 16, Volumen N²3 N¹, Enero - Junio 2019 - Pág. 115 - 137

URL de la Revista: http://revistacientifica.fce.unam.edu.ar/

URL del Documento: http://revistacientifica.fce.unam.edu.ar/index.php?option=com content\&view=article\&id=492\&ltemid=101

ISSN 1668 - 8708 - Versión en Línea

E-mail: revistacientifica@fce.unam.edu.ar
} 
con víveres y abarrotes; restaurantes y comida rápida; taxi urbano; vestimenta y adquisición de equipos de computación.

Acceso: A través de los canales digitales Produbanco procesó 116 millones de transacciones de clientes en el 2016 , el $13 \%$ se efectuaron en las oficinas del banco y el $87 \%$ por medio de canales virtuales. Al final del 2016 el banco contaba con 306 cajeros automáticos. El Banco dispone de puntos de atención en todas las provincias del país, incluyendo áreas de difícil acceso y cantones donde se registran altos índices de pobreza.

Durante el año 2016, la presencia del Banco a nivel nacional aumentó en un 10\%, con la apertura de tres agencias y con la incorporación de 162 establecimientos a la red de corresponsales no bancarios denominada Pagoágil. Durante este periodo se procesaron 1,2 millones de transacciones relacionadas con la entrega del Bono de Desarrollo Humano y 3,6 millones de transacciones de pago de servicios básicos.

\subsubsection{Inclusión Financiera en el Banco del Pacífico}

Banco del Pacifico, en la memoria de sostenibilidad incluye un apartado relacionado con la inclusión financiera. Para Banco del Pacifico, con la inclusión financiera se trata de facilitar el acceso a servicios financieros a los segmentos de la población excluida, mediante la implementación de canales y productos específicos.

\section{Uso (Bancarización)}

Banco del Pacifico tenía 1.671.577 clientes en el 2016, registrándose un incremento del $27,5 \%$ con respecto al 2015 provocado, principalmente, por el aumento de la banca de personas. Durante el 2016 se abrieron 191.000 cuentas de ahorro para los beneficiarios de pensiones alimenticias, segmento vulnerable de la población.

Banco del Pacifico en el 2010 lanzó una cuenta que opera a través de una tarjeta de débito, con el objetivo de bancarizar a las personas que están imposibilitadas de tener acceso a una cuenta de ahorros, por no contar con el flujo de efectivo o requisitos necesarios. Para abrir una cuenta básica se necesita realizar un depósito inicial de USD \$5 y presentar la cédula.

Durante el año 2016, el monto de crédito dirigido a la microempresa fue casi nulo, la mayoría de las colocaciones que realiza esta institución financiera están dirigidas al sector comercial.

Acceso: Durante el 2016, se abrieron 7 agencias nuevas. Además, se instalaron 71 cajeros automáticos, ampliando la red a 570. El Banco en el 2016 amplió su cobertura a nivel nacional en un $39,75 \%$ con relación al 2015, al alcanzar 10.142 puntos de atención distribuidos en todas las provincias del país. Asimismo, en el 2016, se produjo un aumento del uso de la banca móvil en un $36 \%$ y de la banca por internet en un 15\%, mejorando la accesibilidad de los clientes.

\footnotetext{
"Visión de Futuro" Año 16, Volumen N²3 N¹, Enero - Junio 2019 - Pág. 115 - 137

URL de la Revista: http://revistacientifica.fce.unam.edu.ar/

URL del Documento: http://revistacientifica.fce.unam.edu.ar/index.php?option=com content\&view=article\&id=492\&ltemid=101 
Tu Banco Banco Aquí es una red de corresponsales no bancarios del Banco del Pacífico, que está compuesta por cooperativas, farmacias, supermercados, tiendas, cybers y otros establecimientos comerciales. En esta red se puede realizar cobros de servicios básicos. La red le permite al Banco tener cobertura en sectores del país en los que no tenía presencia, incrementándose la bancarización a nivel nacional.

\subsubsection{Inclusión Financiera en el Banco Guayaquil}

La memoria de sostenibilidad 2016 del Banco de Guayaquil fue realizada conforme a las Global Reporting Initiatives versión 4. La institución bancaria, en lo que se refiere a la responsabilidad social, cuenta con un Modelo de Sostenibilidad organizado en 4 ejes: finanzas responsables, ética y transparencia, ambiental y social.

En el segmento de finanzas responsables, la institución financiera rinde cuentas sobre temas relacionados con la educación financiera, la inclusión financiera, las alianzas estratégicas y la capacitación para MIPYMES. Según la memoria 2016, el Banco contribuyó con el ODS8, a través de la entrega de créditos a las PYMES y grandes empresas, para promover el crecimiento económico, inclusivo y sostenible.

Uso (bancarización): Para promover la bancarización e inclusión financiera, el Banco de Guayaquil cuenta con el producto Cuenta Amiga. Es una cuenta básica que se abre con la sola presentación de la cedula de identidad, permitiendo realizar depósitos de dinero y transacciones. Desde su lanzamiento en el 2011, se han abierto 750.000 cuentas, adicionalmente, una tarjeta de débito viene asociada a este producto.

En el año 2016, el segmento de microcrédito representó el 3\%, mientras que el segmento comercial tuvo una participación del $49 \%$ del portafolio total del banco. Al 31 de diciembre de 2016 el monto concedido como microcréditos ascendió a USD $\$ 58$ millones, mientras que en el año 2015 fue de \$USD 83 millones. La participación del crédito otorgado a las PYMES también se vio afectada, al reducirse su participación del 17,13\% en el 2015 al $10,02 \%$ en el 2016. Las cifras anteriores demuestran el alto riesgo que representa para la institución financiera el otorgar crédito a las MIPYMES. En estas circunstancias el microcrédito puede ser todavía más afectado en el momento que la autoridad reguladora disminuya la tasa de interés para este sector.

Acceso: Banco del Barrio corresponde a una red de corresponsales no bancarios (CNB) del Banco de Guayaquil. La institución financiera en el 2016 contaba con 4.910 puntos de servicio en 218 de los 221 cantones del Ecuador, representando una cobertura bancaria nacional del 99\%. Las transacciones realizadas, principalmente, fueron retiros, depósitos, pago de servicios, pago del bono de desarrollo humano, recargas de celular, remesas y recaudos de empresas.

\footnotetext{
"Visión de Futuro" Año 16, Volumen N²3 N¹, Enero - Junio 2019 - Pág. 115 - 137

URL de la Revista: http://revistacientifica.fce.unam.edu.ar/

URL del Documento: http://revistacientifica.fce.unam.edu.ar/index.php?option=com content\&view=article\&id=492\&/temid=101 
En el 2016, los canales más utilizados por los clientes del banco fueron los cajeros automáticos con $31,36 \%$, Banca virtual y electrónica con el $26,93 \%$ y los bancos del barrio con el 21,51\%; en este sentido, se verifica la importancia que otorga la institución financiera a las personas que no habitan en las principales ciudades del país, para que tengan acceso a productos y servicios financieros.

\subsubsection{Inclusión Financiera en el Banco Pichincha}

El Banco Pichincha es el más grande del Ecuador, la decimoprimera Memoria de Sostenibilidad del año 2016, está alineada con la metodología de la Global Reporting Initiative versión cuatro. En este informe se reportan indicadores sociales, económicos y ambientales que corresponden a la gestión realizada por la entidad financiera. Los temas tratados en la memoria se dividen en tres áreas: 1) La ética, transparencia y derechos humanos, 2) finanzas responsables y 3) seguridad, salud y ambiente. La inclusión financiera es analizada en finanzas responsables.

Uso (Bancarización): Banco Pichincha contaba con 3.068.645 clientes a nivel nacional en el 2016, representando un incremento del 0,6\% con respecto al 2015. Durante el 2016 se abrieron aproximadamente 60.000 cuentas de ahorro programado, asimismo, se gestionaron 116.000 microseguros en las ramas de vida, atención hospitalaria, multiriesgo y oncológico, un $20 \%$ más que lo colocado en el 2015. Para atender a grupos vulnerables se diseñaron nuevos productos o se modificaron los existentes, por ejemplo, los créditos para la reactivación por el sismo del 2016, los créditos de refinanciamiento y reestructuración y los créditos para mujeres empresarias o microempresarias.

Para Banco Pichincha, en el 2016 el microcrédito representó el 11,2\%, mientras que el crédito comercial el $43,8 \%$ del total de su portafolio. En este año se convirtió en la primera institución financiera ecuatoriana en obtener la certificación The Smart Campaing versión 2.0 de protección al cliente para el segmento de microfinanzas. Banco Pichincha durante 2016 midió por segunda vez y voluntariamente su gestión de sostenibilidad a través del índice de sostenibilidad Dow Jones Sustentatibily Index, el cual es el referente más conocido a nivel internacional, obteniendo una mejora de 16 puntos frente a la primera medición realizada en 2013.

Microfinanzas individuales de Banco Pichincha se enfoca en la atención de sus clientes en sus propios lugares de trabajo. Durante el 2016, los microcréditos individuales se ofrecieron en el $100 \%$ de las provincias, $82,78 \%$ de las parroquias y en el $100 \%$ de los cantones.

Microfinanzas Grupal se enfoca en formar cajas grupales con personas asociadas que viven o tienen negocios similares, que se conocen entre ellas, y se pueden garantizar solidariamente. Durante el año 2016, Microfinanzas Grupal atendió a 16 de las 17 provincias

\footnotetext{
“Visión de Futuro" Año 16, Volumen No 23 N¹, Enero - Junio 2019 - Pág. 115 - 137

URL de la Revista: http://revistacientifica.fce.unam.edu.ar/

URL del Documento: http://revistacientifica.fce.unam.edu.ar/index.php?option=com_content\&view=article\&id=492\&/temid=101

ISSN 1668 - 8708 - Versión en Línea

E-mail: revistacientifica@fce.unam.edu.ar
} 
sobre el índice de pobreza. Asimismo, de las 11 provincias con baja densidad poblacional, microfinanzas grupal tuvo presencia en 9.

Acceso: Pichincha Mi Vecino es una red de servicios conformada por microempresarios y pequeñas empresas, que con la tecnología que les ofrece el banco, brindan soluciones financieras y no financieras a la comunidad. Banco Pichincha en el 2016 contaba con 11.552 canales de atención a nivel nacional, de los cuales 10.110 correspondían a corresponsales no bancarios (CNB) Mi vecino, 1.174 a canales electrónicos y 268 agencias y puntos físicos. Durante este año se observa una disminución de CNB, al pasar de 14.113 en el 2015 a 10.110 , debido a la optimización de zonas de atención. En este mismo periodo se redujeron los canales físicos de 291 a 268. Durante el 2016 la cobertura de los CNB a nivel nacional representó el $100 \%$ de las provincias, $58,97 \%$ de las parroquias y el $97,27 \%$ de los cantones.

\section{CONCLUSIÓN}

La inclusión financiera es una parte de la responsabilidad social de las instituciones financieras que consiste en impulsar el acceso a los segmentos de la población más pobres y vulnerables a servicios y productos financieros útiles que satisfagan sus necesidades de manera responsable, sustentable y rentable.

Las instituciones financieras analizadas presentan un enfoque instrumentalista de RSE, ya que tienen como objetivo económico la maximización del valor para los accionistas y utilizan a la inclusión financiera como una estrategia de diferenciación para lograr ventajas competitivas.

Las principales guías a las que se encuentran adheridas las instituciones bancarias ecuatorianas son el Pacto Global y los Objetivos de Desarrollo Sostenible, mientras que los indicadores de gestión responsable más utilizados son Global Reporting Initiative (GRI), ISO 26000, Dow Jones Sustainability Index (DJSI) y the Smart Campaing.

En Ecuador, el entorno regulatorio relacionado con la inclusión financiera se ha ido configurando a partir de la Constitución vigente desde 2008, como también a través de la aprobación de leyes, regulaciones y resoluciones relacionadas con las microfinanzas, el uso y acceso a los productos y servicios financieros, medios de pago y con la reducción de las barreras que bloquean la inclusión financiera.

En las instituciones bancarias objeto de estudio no existe una lista genérica de grupos de interés pese a pertenecer a un mismo sector. Para que sean considerados como grupos de interés deben influir o estar influenciados en algún grado por los objetivos de las entidades bancarias, en la medida de que posean poder, legitimidad y urgencia.

\footnotetext{
"Visión de Futuro" Año 16, Volumen N²3 N¹, Enero - Junio 2019 - Pág. 115 - 137

URL de la Revista: http://revistacientifica.fce.unam.edu.ar/

URL del Documento: http://revistacientifica.fce.unam.edu.ar/index.php?option=com content\&view=article\&id=492\&/temid=101 
En las cuatro instituciones financieras, la inclusión se analizó a partir de las memorias de sostenibilidad del año 2016, se tomaron en cuenta las dimensiones uso y accesibilidad del índice multidimensional de inclusión financiera (MIFI), como también el microcrédito. Durante este período se evidencia una mejora del uso y accesibilidad de los productos y servicios financieros.

Durante el año 2016, el microcrédito concedido en tres de las cuatro instituciones bancarias más grandes del Ecuador, representó menos del $5 \%$ del portafolio de créditos. En cambio, durante este mismo periodo el crédito al segmento comercial presentó la mayor participación. La situación de Ecuador, caracteriza a la mayoría de países en desarrollo, en donde la banca formal aun no atiende masivamente a los clientes del segmento de las microfinanzas.

\section{REFERENCIAS}

Aizenman, J., Jijarak, Y., \& Park, D. (2015). Financial Development and output Grouth in Developing Asia and Latin America: A Comparative Sectorial Analysis. National Bureau of Economic Research. Recuperado de http://www.nber.org/papers/w20917.pdf

Asamblea Constituyente. (2008). Constitución de la República del Ecuador. Montecristi.

Recuperado

de

http://www.asambleanacional.gov.ec/documentos/constitucion_de_bolsillo.pdf

Asamblea Nacional. (2014). Código Orgánico Monetario y Financiero. Quito. Recuperado de http://www.politicaeconomica.gob.ec/wp-

content/uploads/downloads/2015/04/CODIGO-ORGANICO-MONETARIO-Y-

FINANCIERO.pdf

Banco Central del Ecuador. (2012). Resolución No. 024-2012. Distrito Metropolitano de Quito.

Recuperado

de

https://contenido.bce.fin.ec/documentos/PublicacionesNotas/Catalogo/Regulaciones/R egulacion24_2012.pdf

Banco del Pacífico. (2016). Memoria de Sostenibilidad. Recuperado de https://www.bancodelpacifico.com/Files/RevistaDigital/MemoriaSostenibilidad2016/Me moria_BdP_2016.pdf

Banco Guayaquil. (2016). Memoria de Sostenibilidad. Recuperado de https://www.bancoguayaquil.com/Portals/0/archivos/GobiernoCorp/Memoria2016.pdf

Banco Mundial. (2016). Recuperado de

http://www.bancomundial.org/es/topic/financialinclusion/overview

\footnotetext{
"Visión de Futuro" Año 16, Volumen N² 23 N¹, Enero - Junio 2019 - Pág. 115 - 137

URL de la Revista: http://revistacientifica.fce.unam.edu.ar/

URL del Documento: http://revistacientifica.fce.unam.edu.ar/index.php?option=com content\&view=article\&id=492\&ltemid=101

ISSN 1668 - 8708 - Versión en Línea

E-mail: revistacientifica@fce.unam.edu.ar
} 
Banco Mundial. (2016). Inclusión Financiera. Recuperado de

http://www.bancomundial.org/es/topic/financialinclusion/overview

Banco Pichincha. (2016). Memoria de Sostenibilidad. Recuperado de https://www.pichincha.com/portal/Portals/0/Transparenciadelnformacion/2016\%20Infor me\%20Anual\%20y\%20Memoria\%20de\%20Sostenibilidad.pdf

Cajiga, J. (2013). El concepto de Responsabilidad Social Empresarial. México: Cemefi. Recuperado de https://www.cemefi.org/esr/images/stories/pdf/esr/concepto_esr.pdf

Cámara, N., \& Tuesta, D. (2014). Measuring Financial Inclusion: A Multidimensional Index. 14(26). Recuperado de https://www.bbvaresearch.com/wpcontent/uploads/2014/10/WP14-26_Financial-Inclusion1.pdf

Corporación Financiera Internacional. (2012). Normas de Desempeño sobre Sostenibilidad Ambiental y Social. Recuperado de http://www.iic.org/es/qui\%C3\%A9nessomos/gesti\%C3\%B3n-del-riesgo-ambiental-y-social\#.WpSetqiWbIW

Cueva, S. (2012). Inclusión social y servicios financieros: una interesante oportunidad. Inclusión Financiera: Aproximaciones teóricos prácticas, 13-16. Recuperado de https://contenido.bce.fin.ec/documentos/PublicacionesNotas/Catalogo/Cuestiones/Inclu sion\%20Financiera.pdf

EIU (Economist Intelligencex Unit). (2016). Microscopio global 2016: Análisis del entorno para la inclusión financiera. Recuperado de https://publications.iadb.org/bitstream/handle/11319/7988/Microscopio-global-2016Analisis-del-entorno-para-la-inclusion-financiera.pdf?sequence=2\&isAllowed=y

Ekos. (2017). Ranking Financiero 2017. Recuperado de http://www.ekosnegocios.com/negocios/especiales/documentos/financiero2017.pdf

Elkington, J. (1994). Towards the Sustainable Corporation: Win-Win-Win Business Strategies for Sustainable Development. California Management, 36(2), 90-100. doi:https://doi.org/10.2307/41165746

Global Banking Aliance for Women. (2018). Recuperado de http://www.gbaforwomen.org/mymembers/

Global Reporting Initiative (GRI). (2011). GRI e ISO 26000: Cómo usar las Directrices del GRI, en conjunto con la Norma ISO 26000. Amsterdam. Recuperado de https://www.globalreporting.org/resourcelibrary/Spanish-GRI-ISO-Linkage-DocumentUpdated-Version.pdf

Global Sustainability Standards Board. (2016). GRI 101: Fundamentos 2016. Ámsterdam. Recuperado de https://www.globalreporting.org

Guerrero, R., Espinosa, S., \& Focke, K. (2012). Aproximación a una Visión Integral de la Inclusión Financiera: Aspectos conceptuales y casos prácticos. Inclusión Financiera:

\footnotetext{
"Visión de Futuro" Año 16, Volumen Nº 23 N¹, Enero - Junio 2019 - Pág. 115 - 137

URL de la Revista: http://revistacientifica.fce.unam.edu.ar/

URL del Documento: http://revistacientifica.fce.unam.edu.ar/index.php?option=com content\&view=article\&id=492\&ltemid=101 
Aproximaciones teóricas y prácticas, 19-50. Recuperado de https://contenido.bce.fin.ec/documentos/PublicacionesNotas/Catalogo/Cuestiones/Inclu sion\%20Financiera.pdf

International Finance Corporation. (2013). The Equator Principles. Retrieved from https://ifcext.ifc.org/ifcext/Pressroom/IFCPressRoom.nsf/0/41A62AAA1CEA564085257 1A4004EBBFB?OpenDocument

ISO. (2010). ISO 26000: 2010(es). Recuperado de https://www.iso.org/obp/ui\#iso:std:iso:26000:ed-1:v1:es

Junta Bancaria del Ecuador. (2008). Resolución No JB-2008-1150. Guayaquil. Recuperado de

http://web.sbs.gob.ec/medios/PORTALDOCS/downloads/normativa/2008/Junta_Banca ria/resol_JB-2008-1150.pdf

Junta de Política y Regulación Monetaria y Financiera. (2014). Resolución No. 005-2014-M. Distrito Metropolitano de Quito. Recuperado de https://www.juntamonetariafinanciera.gob.ec/PDF/Resolucion\%20No.\%20005-2014M.pdf?dl=0

Junta de Política y Regulación Monetaria y Financiera. (2018). Resolución No. 437-2018-F. Recuperado de https://www.juntamonetariafinanciera.gob.ec/PDF/Resolucion-4372018-F.pdf?dl=0

Levine, R., Loaiza, N., \& Beck, T. (2000). Financial intermediation and growth:Causality and causes. Journal of Monetary Economics (46), 31-77.

Marulanda. P. (2014). Prácticas de Responsabilidad Social Empresarial de la Banca Colombiana: Estudio Documental de Bancolombia, Banco de Bogotá y Davivienda. Recuperado de http://www.bdigital.unal.edu.co/48894/1/43839412.2015.pdf

Mazer, Rafe, \& Mckee, K. (2017). Consumer Protection in Digital credit. CGAP(108), 24. Recuperado de http://www.cgap.org/sites/default/files/Focus-Note-ConsumerProtection-in-digital-Credit-Aug-2017.pdf

Mitchell, R., Agle, B., \& Wood, D. (1997). Toward a Theory of Stakeholder Identification and Salience: Defining the Principle of Who and What Really Counts. Academy of Management, 22(4), 853-886. Recuperado de https://www.jstor.org/stable/pdf/259247 Moya, C. (2011). Presentación Banca de las Oportunidades: Transparencia, protección al consumidor e inclusión financiera: Experiencias prácticas de Colombia.

Naciones Unidas. (2016). Recuperado de http://www.sela.org/media/2262361/agenda-2030y-los-objetivos-de-desarrollo-sostenible.pdf

Naciones Unidas. (2018). Recuperado de http://www.un.org/sustainabledevelopment/es/

Noé, C., Buraschi, M., \& Peretti, M. (2015). Orientación de los empresarios de CórdobaArgentina hacia la sustentabilidad y responsabilidad social empresarial: identificación de

"Visión de Futuro" Año 16, Volumen N²3 N¹, Enero - Junio 2019 - Pág. 115 - 137

URL de la Revista: http://revistacientifica.fce.unam.edu.ar/

URL del Documento: http://revistacientifica.fce.unam.edu.ar/index.php?option=com_content\&view=article\&id=492\&ltemid=101

ISSN 1668 - 8708 - Versión en Línea

E-mail: revistacientifica@fce.unam.edu.ar 
variables asociadas a cada constructo. Contaduría y Administración, 61, 84-105. doi:https://doi.org/10.1016/j.cya.2015.10.001

OECD. (2011). G20 High-Level Principles on Financial Consumer Protection. Paris. Recuperado de http://www.oecd.org/daf/fin/financial-markets/48892010.pdf

OECD. (2013). Financial Literacy and Inclusion. Recuperado de https://www.oecd.org/daf/fin/financial-

education/TrustFund2013_OECD_INFE_Fin_Lit_and_Incl_SurveyResults_by_Country _and_Gender.pdf

Pacto Global Red Colombia. (2018). Qué es el Pacto Global? Recuperado de http://www.pactoglobal-colombia.org/pacto-global-colombia/que-es-pacto-globalcolombia.html

Pineda, M. (2014). Negocios y Sostenibilidad en la Base de la Pirámide. Punto de Vista, 5(9), 95-116. doi:10.1108/S2051-5030(2013)0000012009

Prahalad, C. (2005). The fortune at bottom of the Pyramid . New Yersey: Board.

Presidencia de la Repúbica del Ecuador. (2017). Ley Orgánica para impulsar la reactivación económica del Ecuador. Quito. Recuperado de http://capig.org.ec/documentos/ley_organica_para_impulsar_la_reactivacion_economic a_del_ecuador.pdf

Presidencia de la República. (2011). Ley de Economía Popular y Solidario y del Sector Financiero Popular y Solidario. Distrito Metropolitano de Quito. Recuperado de http://www.seps.gob.ec/documents/20181/25522/Ley\%20Orga\%CC\%81nica\%20de\%2 0Economi\%CC\%81a\%20Popular\%20y\%20Solidaria.pdf/0836bc47-bf63-4aa0-b945b94479a84ca1

Produbanco.

(2016).

Memoria

RSE.

Recuperado

de https://www.produbanco.com.ec/qui\%C3\%A9nes-somos/responsabilidad-social/

Rivera, H., \& Malaver, M. (2011). La organización: los stakeholders y la responsabilidad social. Centro de Estudios Empresariales para la Perdurabilidad (CEEP)(97), 1-34. Recuperado de http://www.urosario.edu.co/urosario_files/a0/a019d4bc-3670-4966-881cccaabf47d85c.pdf

RobecoSam. (2018). Recuperado de http://www.sustainability-indices.com/index-familyoverview/djsi-family-overview/index.jsp

Rodriguez, N., \& Segura, M. (2013). Análisis de la aplicación de la RSE en el sector financiero en Colombia, en particular en relación con las políticas de inclusión financiera. Bogotá: Universidad EAN. Recuperado de http://repository.ean.edu.co/bitstream/handle/10882/5304/RodriguezNeslie2013.pdf?se quence $=1$

\footnotetext{
"Visión de Futuro" Año 16, Volumen N²3 N¹, Enero - Junio 2019 - Pág. 115 - 137

URL de la Revista: http://revistacientifica.fce.unam.edu.ar/

URL del Documento: http://revistacientifica.fce.unam.edu.ar/index.php?option=com content\&view=article\&id=492\&ltemid=101 
Rubio, G., \& Fierro, F. (2016). La RSE: una teoría, diferentes visiones aplicadas. Administración \& Desarrollo, 46(2), 160-174. Recuperado de file://C:/Users/acost/Downloads/77-Texto\%20del\%20art\%C3\%ADculo-1598-1-1020170629.pdf

Sahay, R., Cihák, M., N’Diaye, P., \& Barajas, A. (2015). Reconsiderando la Profundización Financiera: Eatabilidad y Crecimiento de los Mercados Emergentes. International Monetary Fund. doi:10.5089/9781513597836

Slaper, T., \& Hall, T. (2011). The Triple Bottom Line: What Is It and How Does It Work. Indiana Business Review, 86(1), 4-8. Recuperado de http://www.ibrc.indiana.edu/ibr/2011/spring/article2.html

The Smart Campaign. (2011). Los Principios de Protección al Cliente. Recuperado de http://www.smartcampaign.org/sobre-la-campana/microfinanciacion-smart-y-principiosde-proteccion-del-cliente

United Nations Global Compact. (2018). Recuperado de https://www.unglobalcompact.org/what-is-gc/mission/principles

\section{RESUMEN BIOGRÁFICO}

\section{Galo Ramiro Acosta Palomeque}

Magister en Gerencia Empresarial por la Escuela Politécnica Nacional de Ecuador, actualmente realizando estudios de Doctorado en Ciencias de la Administración en la Universidad Nacional de la Plata en Argentina, Docente a nivel de pregrado y posgrado por alrededor de 18 años, actualmente docente a tiempo completo de la Universidad de las Fuerzas Armadas ESPE, ex director de la Carrera de Ingeniería en Finanzas y Auditoria en las modalidades presencial y a distancia como también ex coordinador de la Maestría en Administración de Empresas. 